\title{
نظام آلي لمراقبة الانتاج في هصانع الملابس الجاهزة
}

\section{Computer-based System for Production Monitoring in Ready Made Garments' Factories}

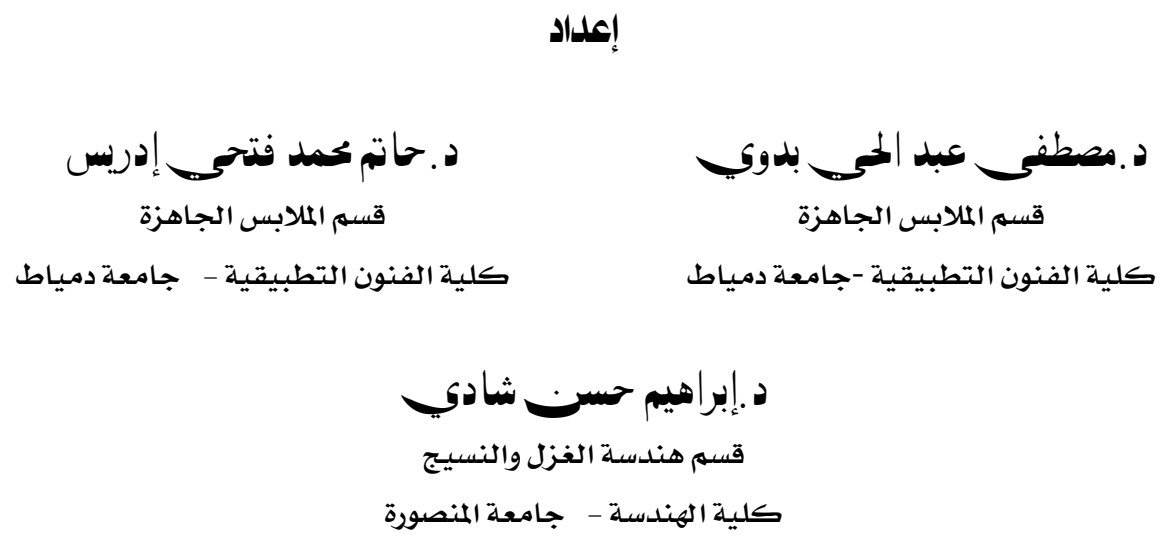

مجلة بحوث التربية النوعية ـ جامعة المنصورة

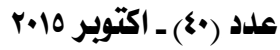




\section{نظام آلي لمراقبة الانتاج في هصانع الملابس الجاهزة}

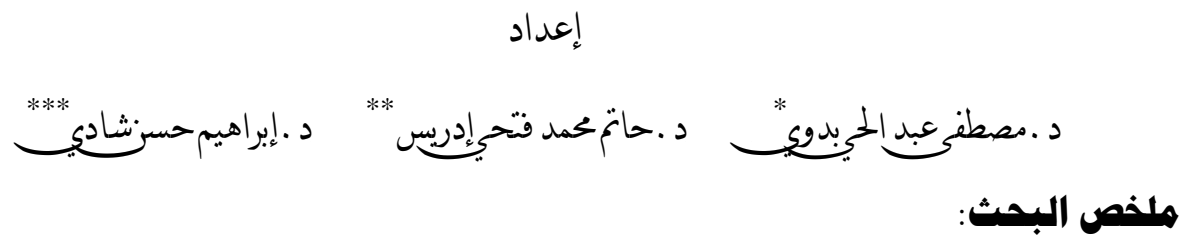

تعتبر صـناعة الملابسس الجـاهزة مـن الـصناعات الـتي تحتـاج الى تطـوير متلاحسق لمسايرة

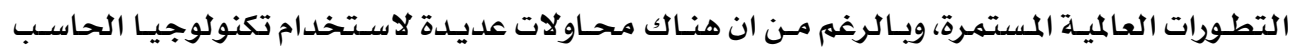

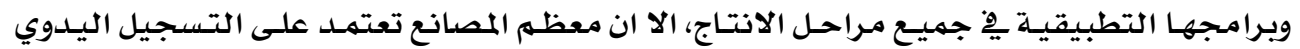

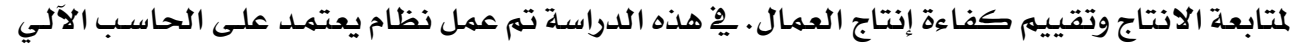

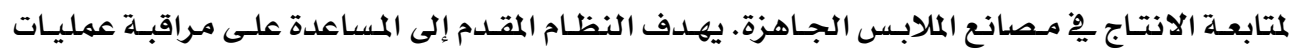

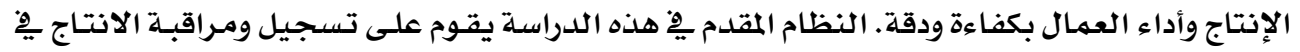

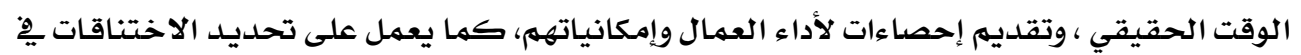

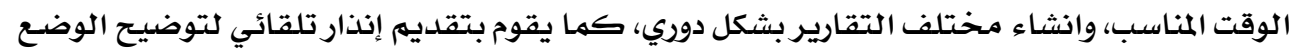

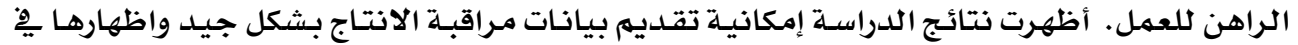

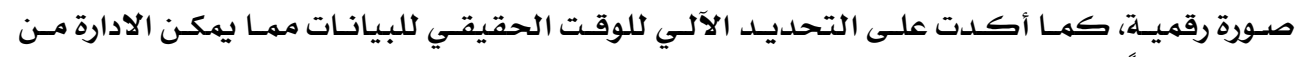

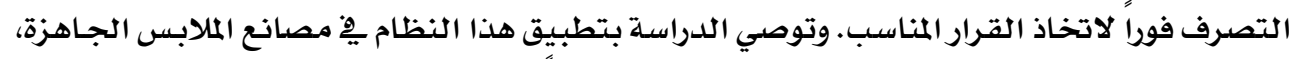

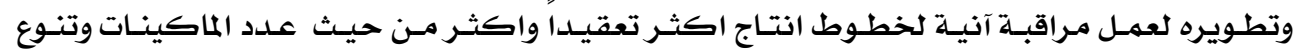
العمليات بشكل مستمر ومتوازن.

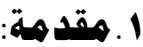

ِِِ ظل المتغيرات التنافسية العالمية الراهنة تحتاج صناعة الملابس الجـاهزة الى توجيـه العلـم

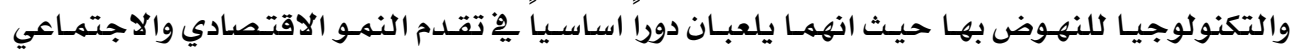

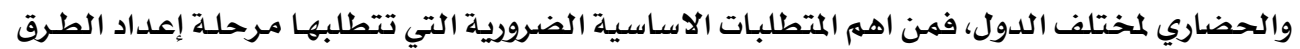

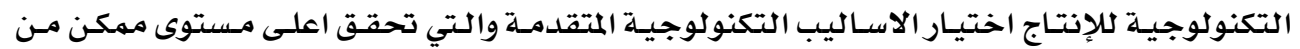

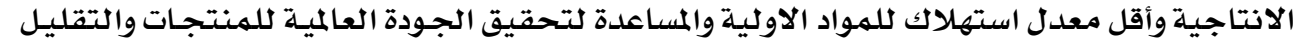

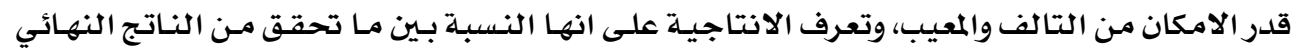

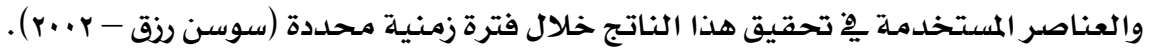

ققسم الملابس الجاهزة - كلية الفنون التطبيقية -جامعة دمياط

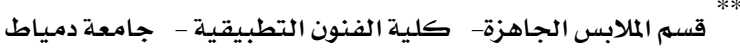
قسم هندسة الغزل والنسيـج- كلية الهندسة - جامعة المنصورة 
وتعتبر صـناعة الملابس الجـاهزة مـن الـصناعات الـتي تحتـاج الى تطـوير متلاحسق لمسايرة

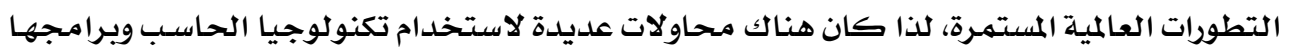

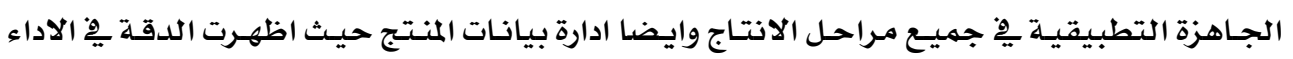

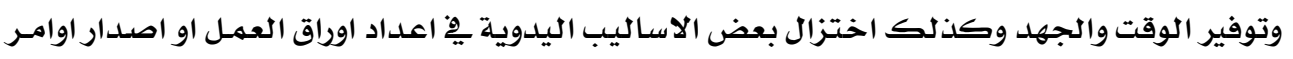

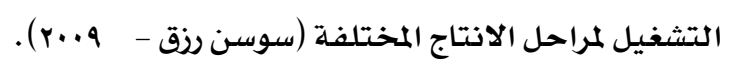

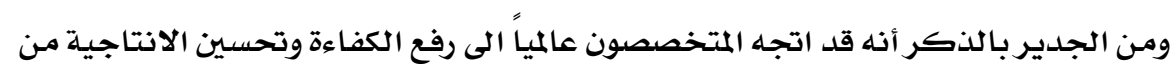

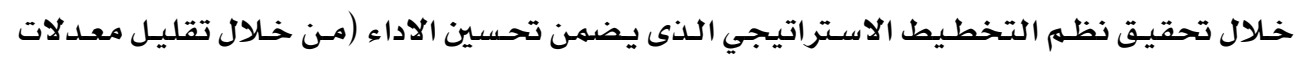

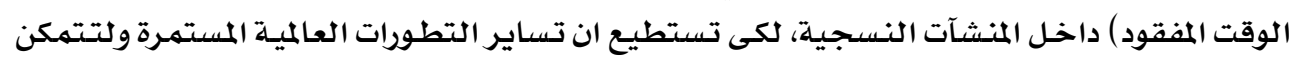

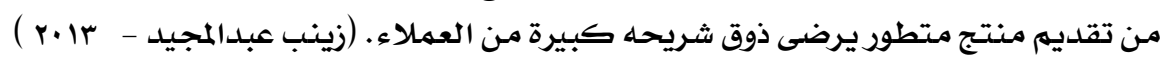

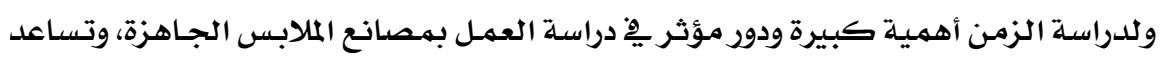

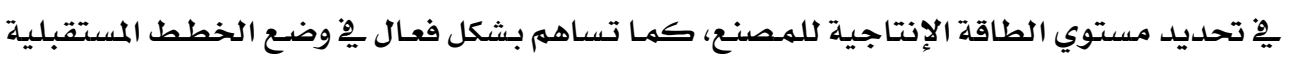

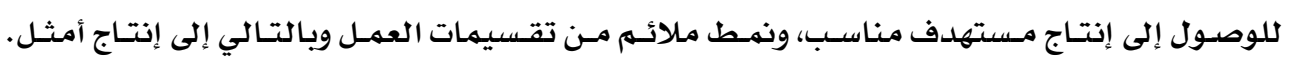

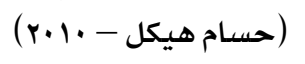

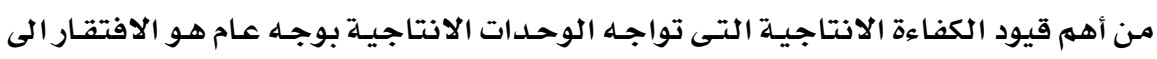

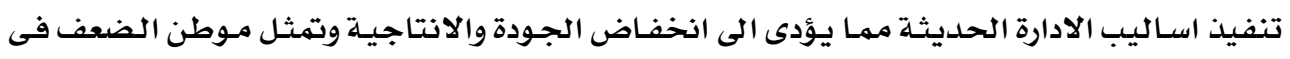

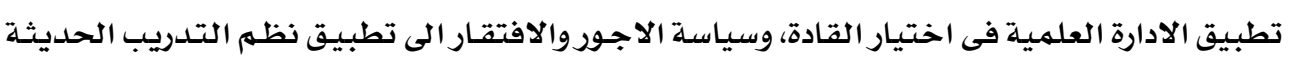

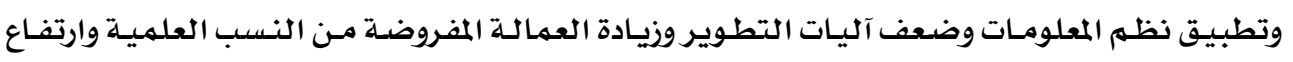

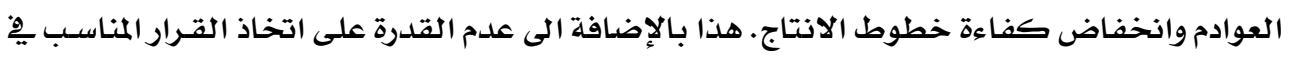

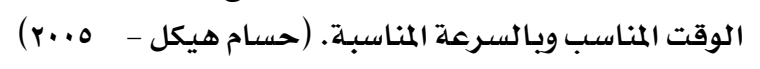

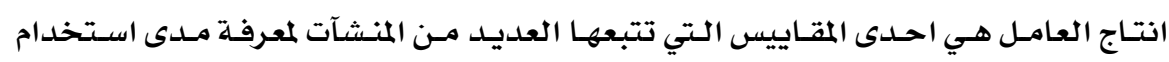

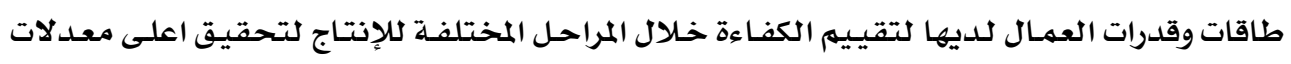

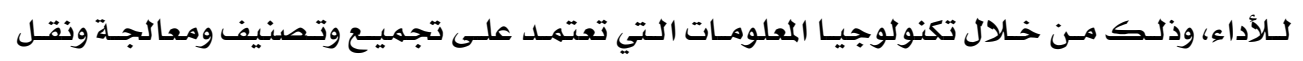

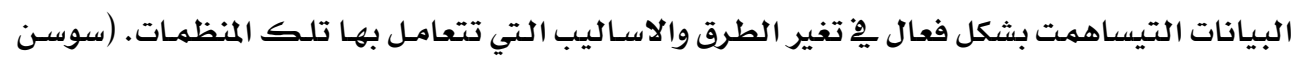

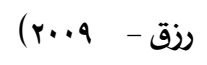

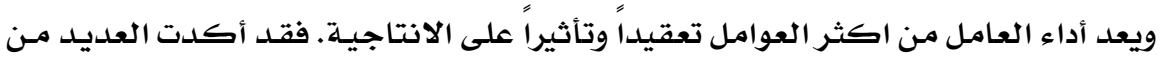

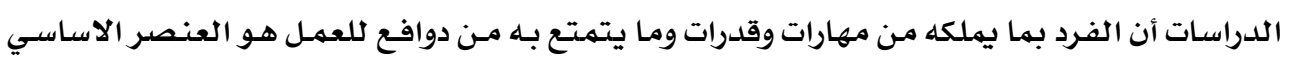

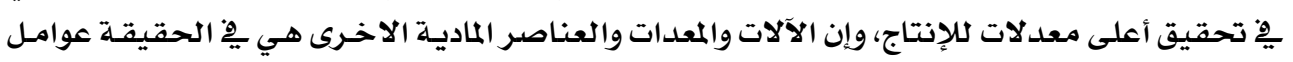

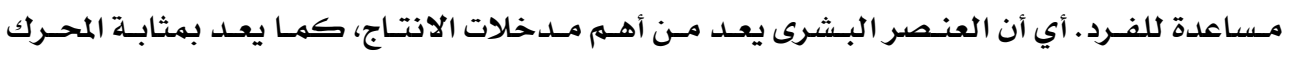

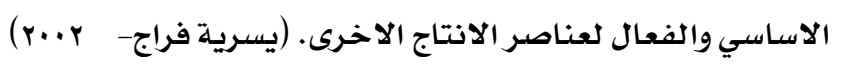

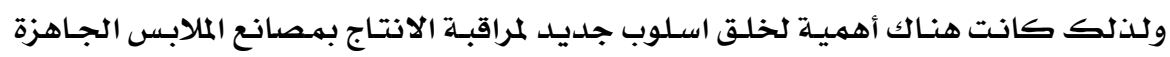

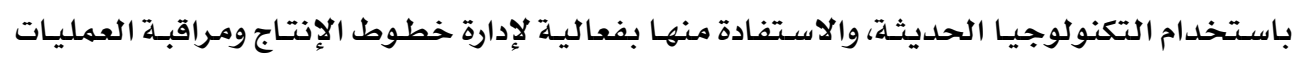




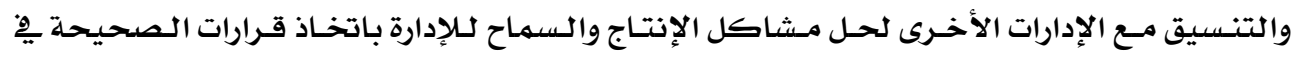
الوقت المناسب.

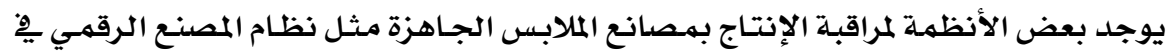

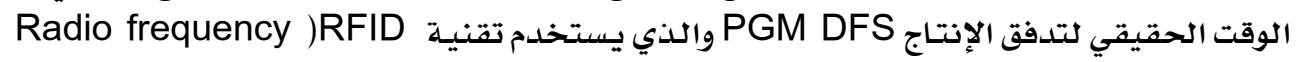

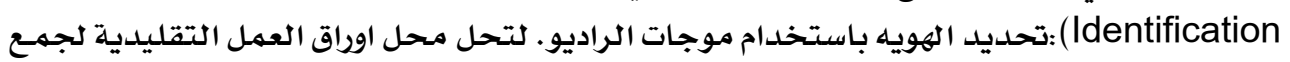

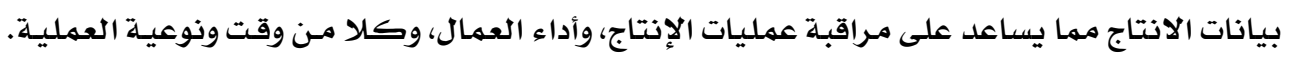

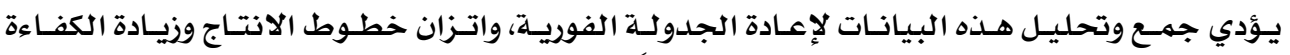

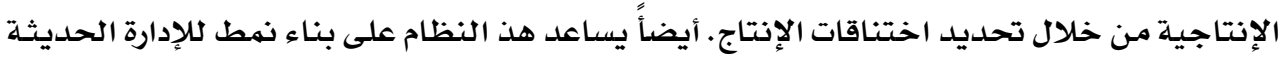
وبيئة الإنتاج الرقمي بشفافية عالية، ويِ الوقت الحقيقي عن طريق التفاعل التام والتنسيق الفعال.

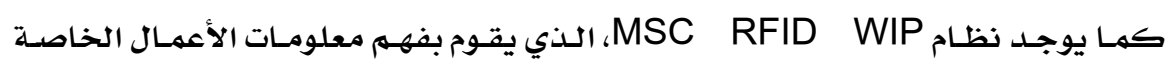
بمؤسسة على نحو أفضل، مـع القدرة على تقديم التقارير يْ الوقت الحقيقي وأدوات تحليل البيانات.

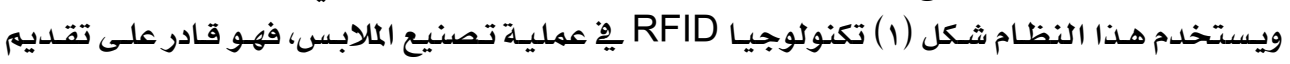

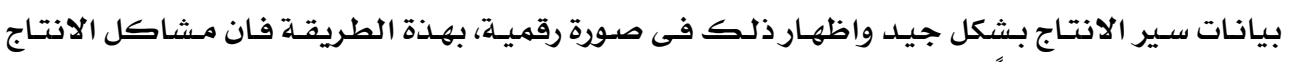

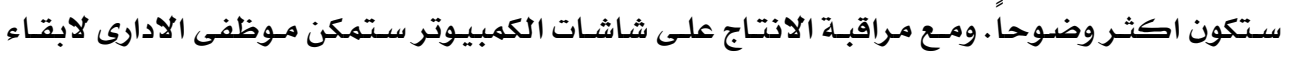

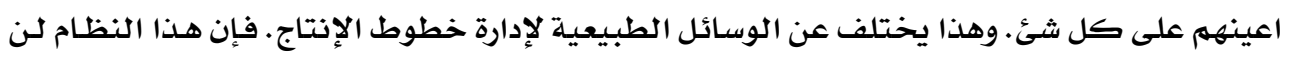

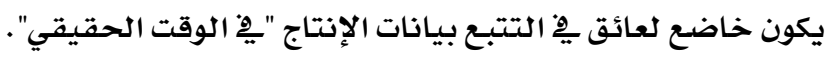
http://www.zymmetry.com/news/tc/18-1/rfid

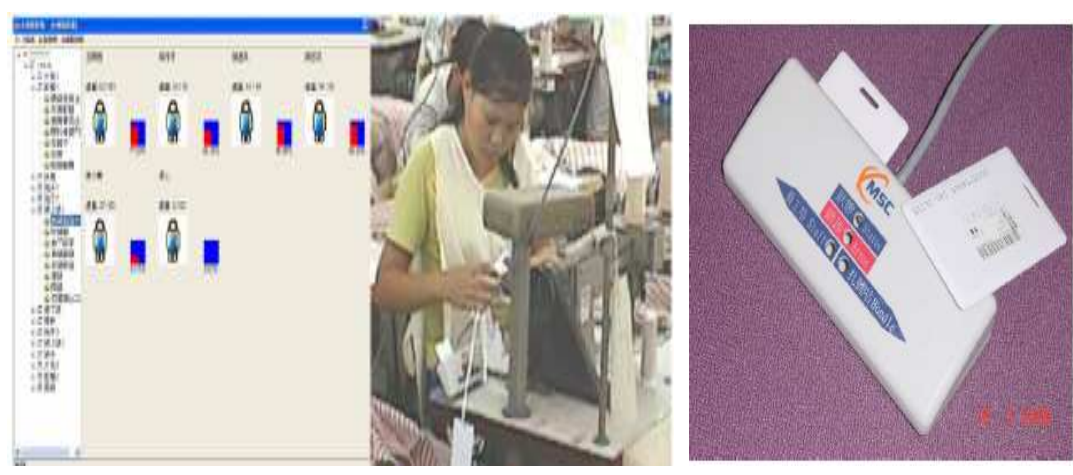

شكل (1) نظام MSC متابعه العمليات الانتاجية وتحليل البيانات

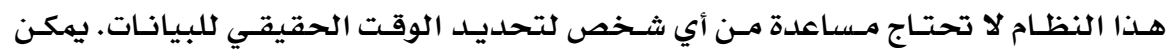

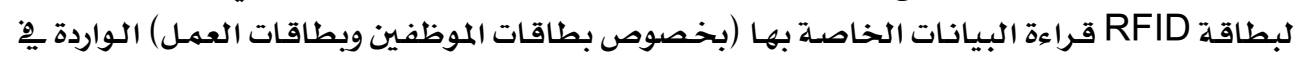

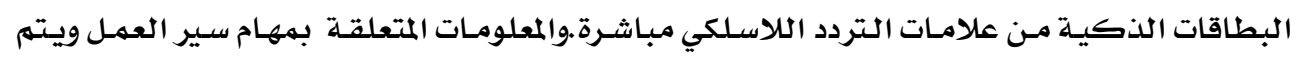


تخزينها حيث ان المعلومات تسير يِّ النظام بأكمله بهذه الطريقة.يجـب توفير الوقت الحقيقي بدقة

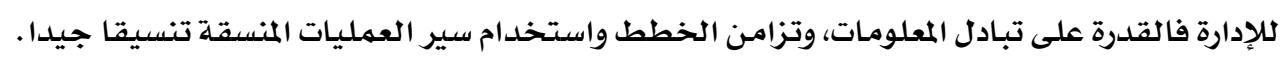

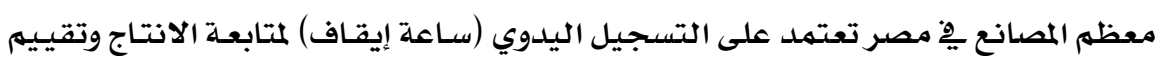

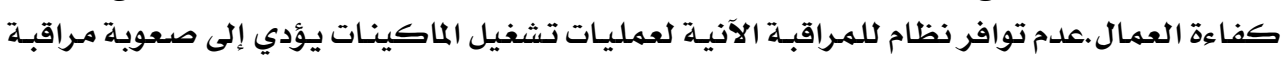

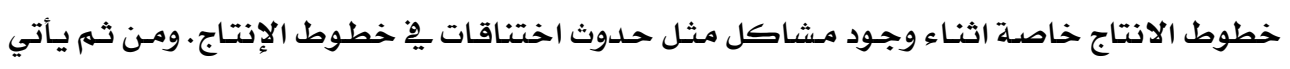

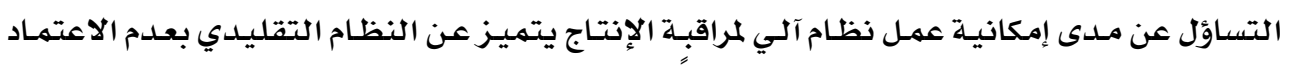

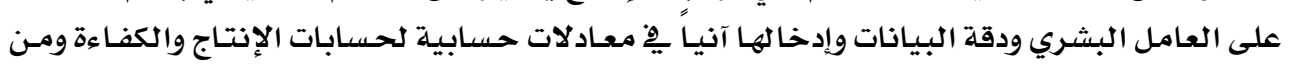

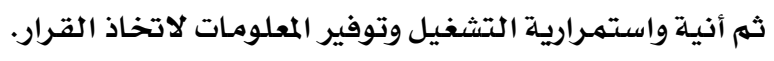

\section{ولتحقيق ذلك تم تقسيم العمل ِِّ هذا البحث على المحاور الثلاث التالية:}

1- وصف وتحليل أساليب ونظم متابعة الانتاج بمصانع الملابس الجاهزة.

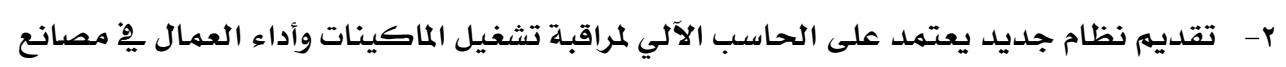

الملابس الجاهزة وتطبيقه على المستوى التجريبي.

r- المقارنة بين النظام القائم والنظام المقترح.

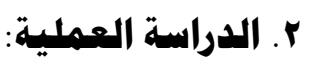

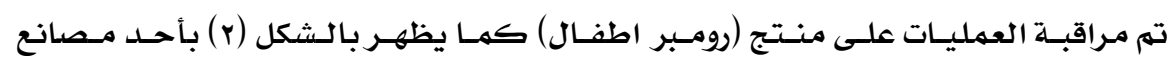
المابس الجاهزة.

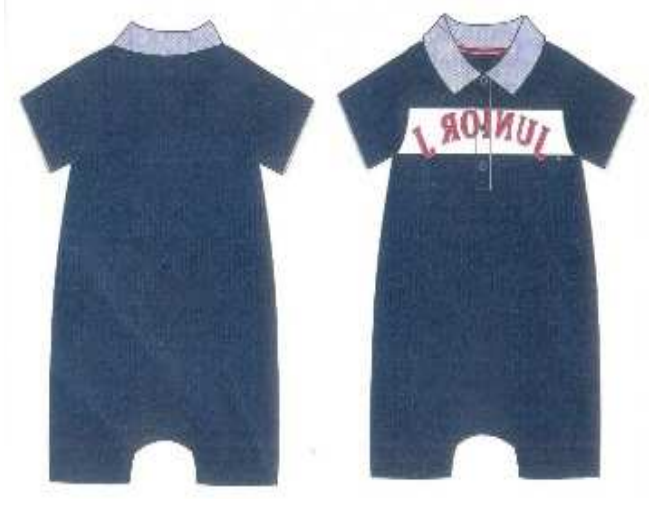

شكل (Y) صورة الموديل محل الدراسة(رومبر اطفال).

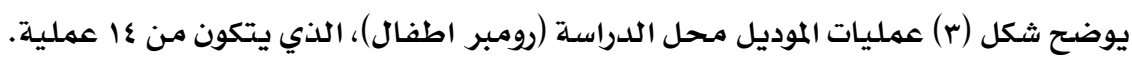




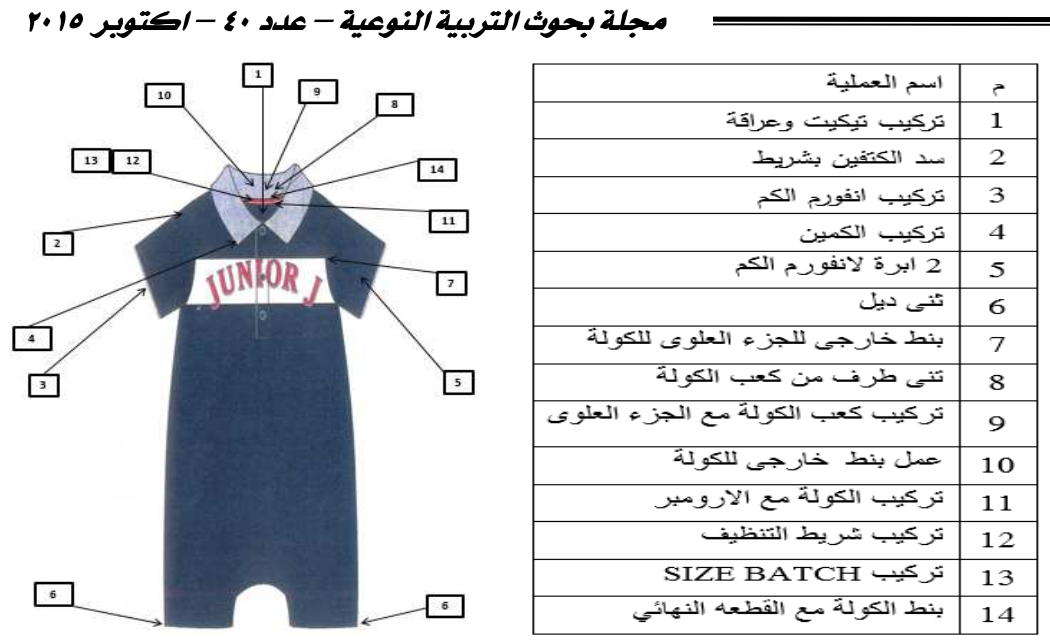

ثكل (r) عمليات الموديل محل الدراسة.

نظام مراقبة عمليات التشفيل المقترح:

فكرة هـذا النظـام مطبقـة بالفعل على المستوى التجـاري (على سـبيل المثل PGM DFS)،

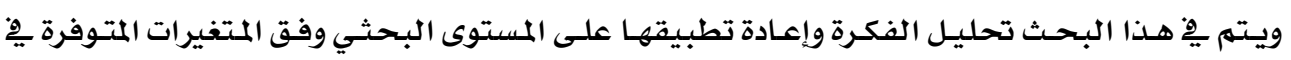
حدود البحث تصث.

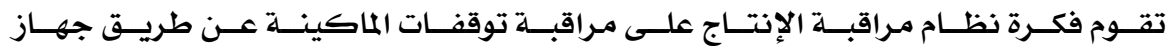

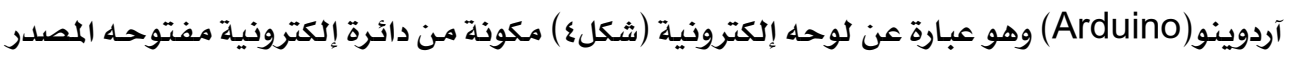

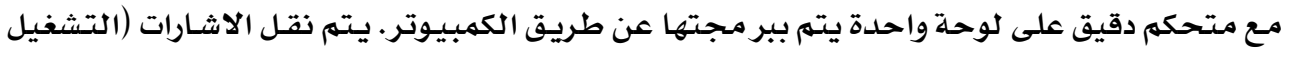

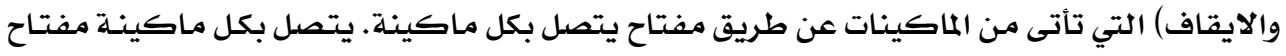

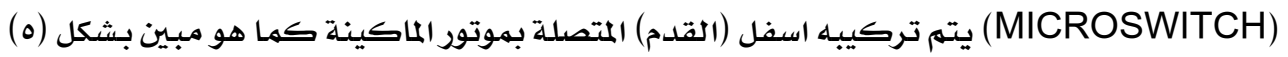

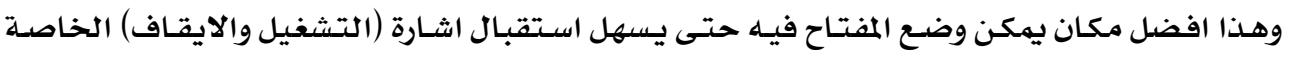

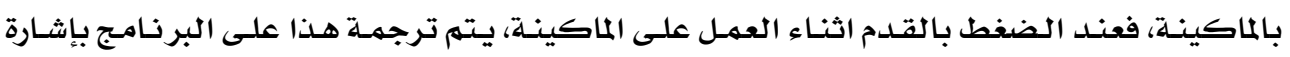

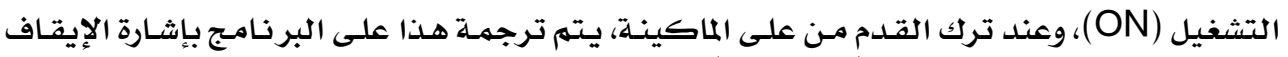

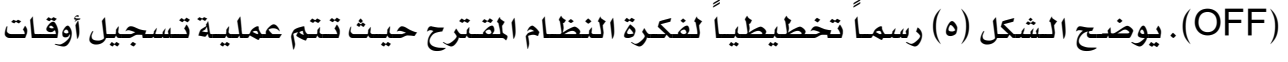

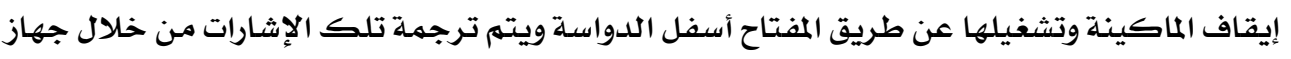

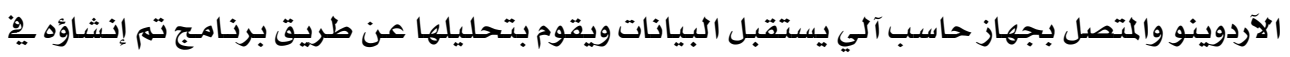

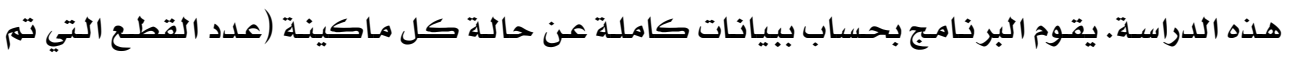

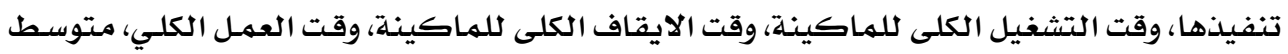

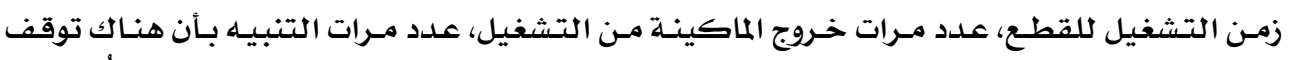

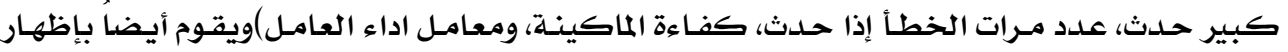

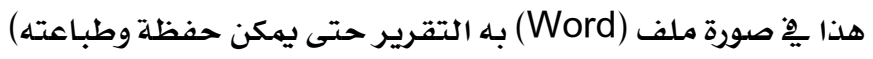




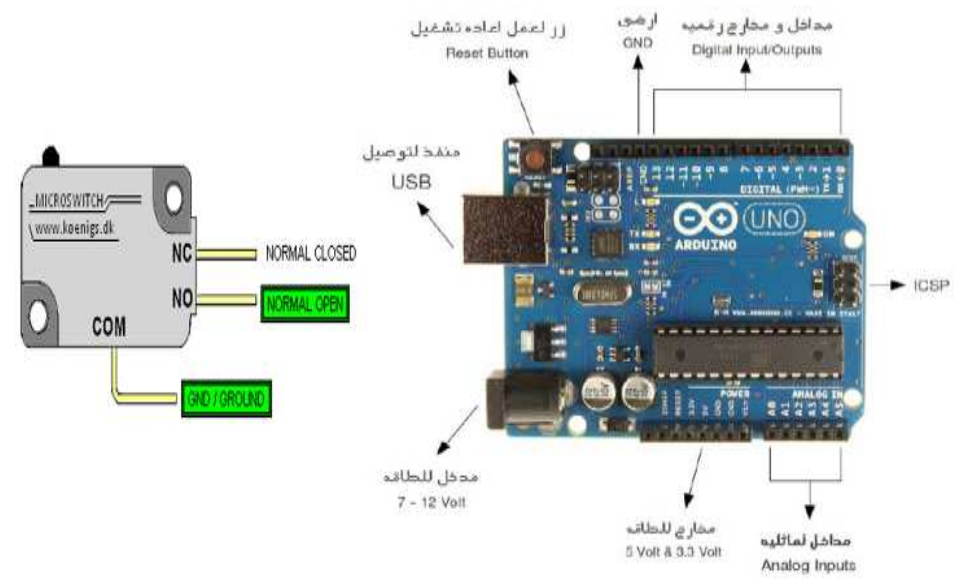

ثكل (ع) جهاز الاوددوينو والمفتاح الذى ينقل الاثارات من الماكينه.

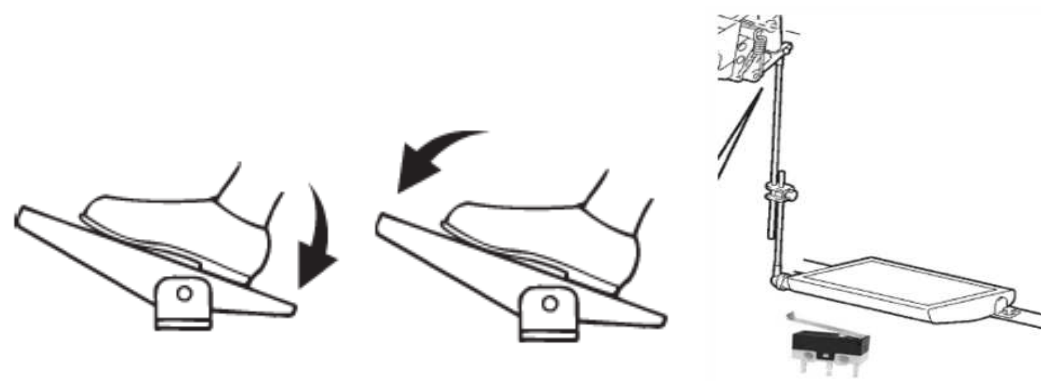

ثكل (0) طريقة وضع المفتاح (MICROSWITCH) بالماكينة.

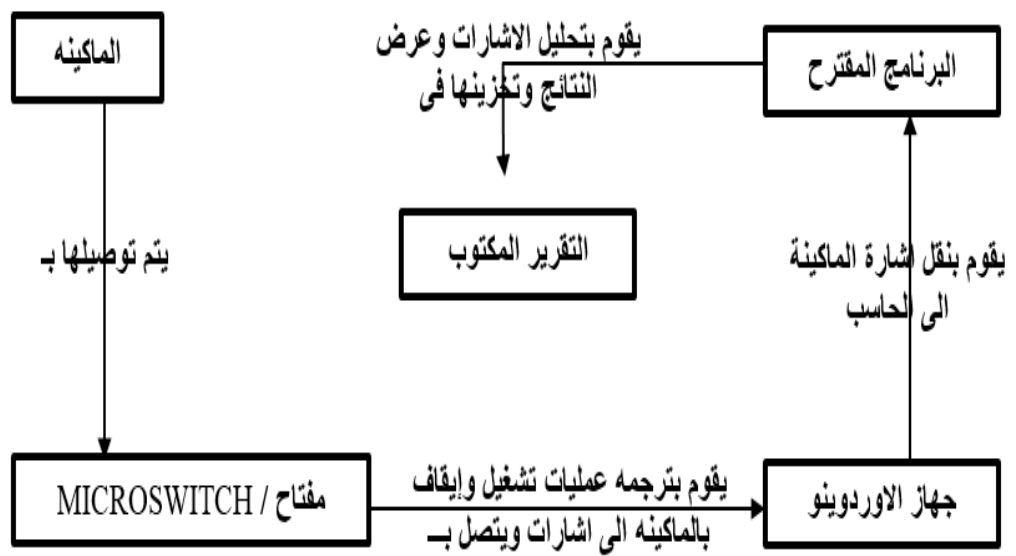

ثكل (ج) رسم تخطيطي للنظام المقترح لمراقبة عمليات التشغيل. 


$$
\begin{aligned}
& \text { يتم تشغيل البرنامج وعمل الحسابات وفقا لما يلي: }
\end{aligned}
$$

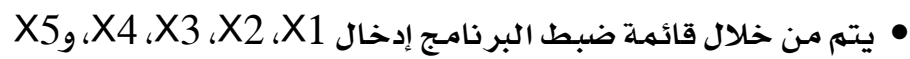

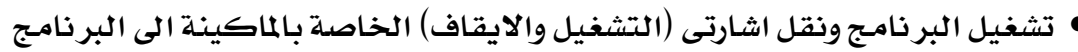

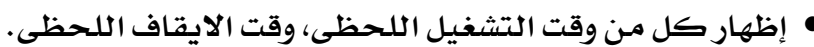

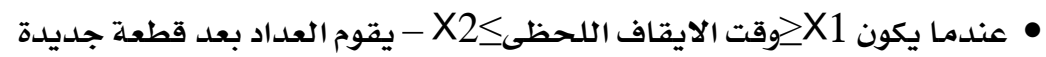

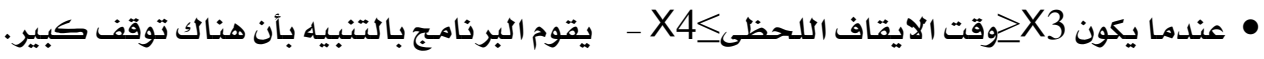

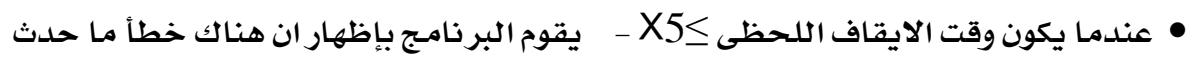

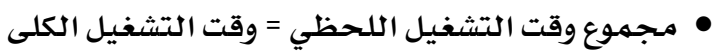

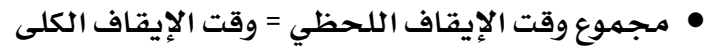

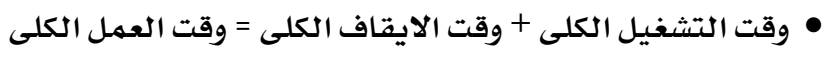

$$
\begin{aligned}
& \text { وقت التشفيل الكلى }
\end{aligned}
$$

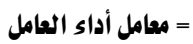

= متوسط زمن تشفيل القطعة =
علد القطع المتوقع تنفيذها فى اليوم

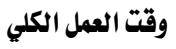

\begin{tabular}{c} 
عدد القطع المنفذة عدد القطع المتوقع تنفيذها فى اليوم العمل الكلي \\
\hline
\end{tabular}

عدد القطع المنفذة فى اليوم

r. النتائج وهناقشاتها:

ronline monitoring system (OMS) البرنامج المقترح

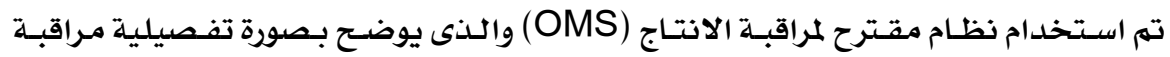

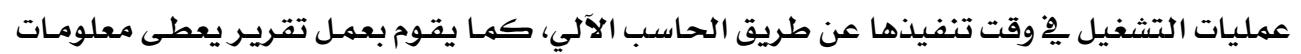

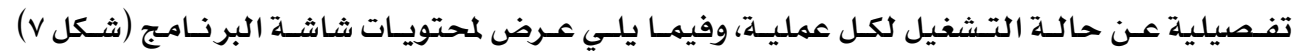
وشكل التقرير: 


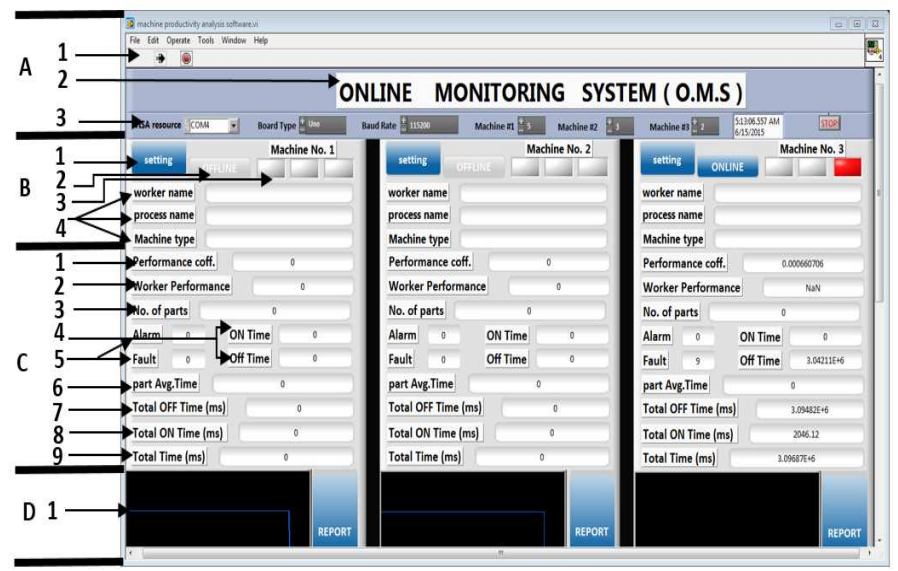

شكل (VMS) شاشة البرنامج المقترح (OM)

شاشة البرنامجج تم تقسيمها الى عده مناطق:

• المنطقة "A": وهذه المنطقة المسئولة عن تشغيل البرنامج واعدادات جهات جهاز الاوردوينو، وتحتوى على:

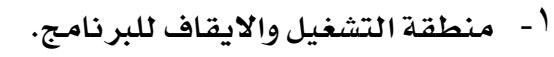

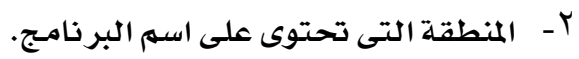

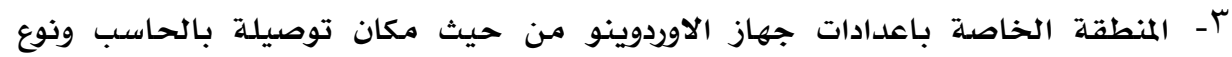

الاوردوينو، ومكان توصيل المفاتيح عليه.

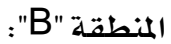

وهذه المنطقة المسئولة عن اعدادات الادخال الخاصة بالبرنامـج، وتحتوى على:

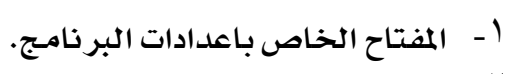

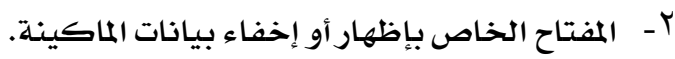

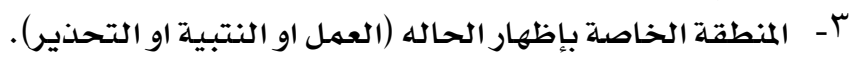

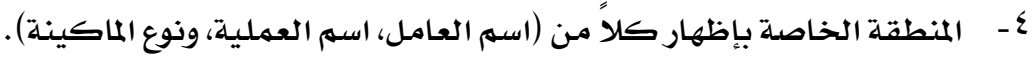

المنطقة "C"

وهذه المنطقة المسئولة عن عملية الاخراج الخاصة بالبرنامـج، وتحتوى على:

$$
\begin{aligned}
& \text { r - معامل الاداء } \\
& \text { 1- كفاءة العامل } \\
& \text { ؟- وقت التشغيل والايقاف } \\
& \text { ب- مد - عدد القطع }
\end{aligned}
$$

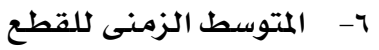

$$
\begin{aligned}
& \text { ه- عدد مـرات التتبيه والتحدير }
\end{aligned}
$$

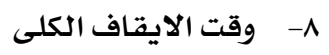

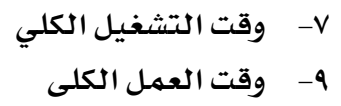


وهذه المنطقة بها رسهم بياني يوضـح إثـارة التشغيل والايقـاف اللحظيـة والخاصسة بالماكينـة،

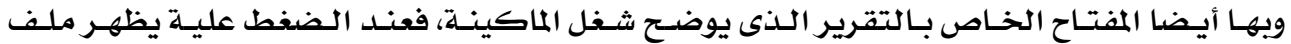
به التقرير حتى يهكن حفظة وطباعته. (Word) rـ r r تتائج مراقبة بعض عمليات التشفيل بالطريقتين:

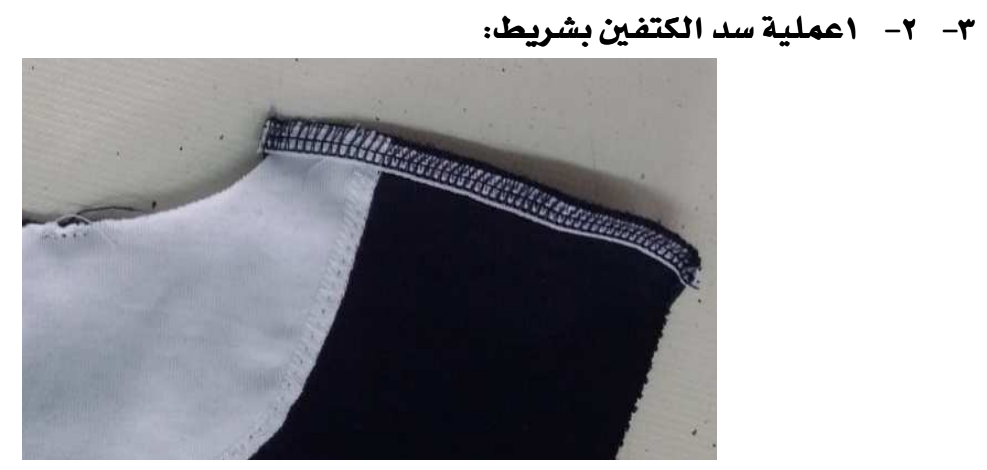

شكل (^) عملية سد الكتفين بشريط

• الطريقة التقليدية: باستخدام الطريقة التقليدية تم رصد زمن تشغيل عدد (ی قطعة) لعملية سد كتفين بثريط بمقدار(680.3 ثانية) وكان متوسط زمن التقلة التشغيل للقطع (24.3 ثانية)

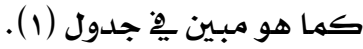

جدول(1) نتائج مراقبة عملية سد كتفين بشريطبالطريقة التقليدية.

\begin{tabular}{|c|c|}
\hline 28 & عدد القطع \\
\hline ثانية60.3 & المقت المستفرق \\
\hline ثانية24.3 & متوسط زمن تشفيل القطعه \\
\hline
\end{tabular}

• الطريقة المقترحة: باستخدام نظام المراقبة الآلي تم رصد زمن تشغيل عدد (Nا) قطعة لعملية

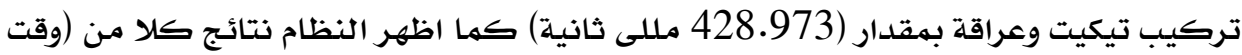

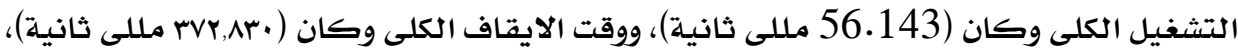

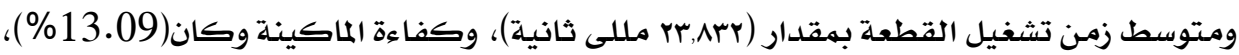

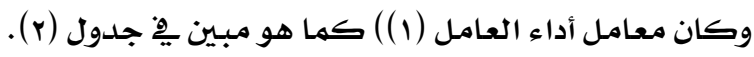


جدول(Y) نتائج مراقبة عملية سد كتفين بشريط بالطريقة المقترحة (OMS).

\begin{tabular}{|c|c|c|c|}
\hline الزمن الكلى (بالمللى ثانية) & وقت ايقاف (بالمللى ثانية) & وقت تشفيل (بالمللى ثانية) & عدد القطع \\
\hline 22865 & 19009 & 3856 & 1 \\
\hline 20743 & 17160 & 3583 & 2 \\
\hline 21797 & 18330 & 3467 & 3 \\
\hline 19903 & 17002 & 2901 & 4 \\
\hline 24313 & 21329 & 2984 & 5 \\
\hline 20637 & 17644 & 2993 & 6 \\
\hline 23447 & 20681 & 2766 & 7 \\
\hline 23976 & 20779 & 3197 & 8 \\
\hline 33415 & 29483 & 3932 & 9 \\
\hline 23691 & 20385 & 3306 & 10 \\
\hline 21714 & 18944 & 2770 & 11 \\
\hline 20144 & 17456 & 2688 & 12 \\
\hline 27178 & 24434 & 2744 & 13 \\
\hline 22682 & 20008 & 2674 & 14 \\
\hline 33528 & 30687 & 2841 & 15 \\
\hline 24882 & 21079 & 3803 & 16 \\
\hline 19402 & 16512 & 2890 & 17 \\
\hline 24656 & 21908 & 2748 & 18 \\
\hline 56143 & \multicolumn{3}{|c|}{ وقت التشفيل الكلى (بالمللى ثانية) } \\
\hline 372830 & \multicolumn{3}{|c|}{ وقت الايقاف الكلى (بالمللى ثانية) } \\
\hline 428973 & \multicolumn{3}{|c|}{ اجمالى الوقت المستفرق للقطع (بالمللى ثانية) } \\
\hline 23831.83333 & \multicolumn{3}{|c|}{ متوسط زمن تشفيل القطعه (بالمللى ثانية) } \\
\hline 13.09 & \multicolumn{3}{|c|}{ كفاءة الماكينة (\%) } \\
\hline 1 & \multicolumn{3}{|c|}{ معامل اداء العامل } \\
\hline
\end{tabular}




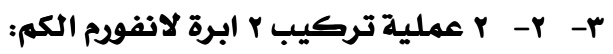

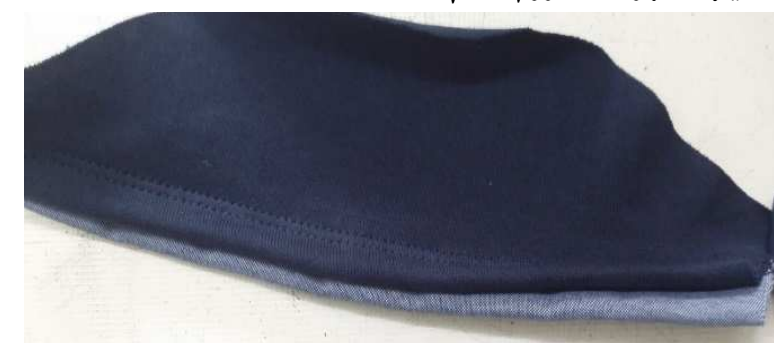

\section{شكل (9) عملية تركيب r ابرة لانفورم الكم}

• الطريقة التقليدية: باستخدام ساعة الايقاف تم رصد زمن تشغيل عدد (اء قطعة) لعملية

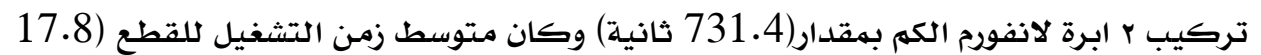

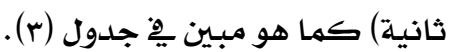

جدول(r) نتائج مراقبة عملية تركيب r ابرة لانفورم الكم بالطريقة التقليدية.

\begin{tabular}{|c|c|}
\hline 28 & عدد القطع \\
\hline ث229.9 & الوقت المستفرق \\
\hline$\dot{\leftrightarrow} \Lambda, r$ & متوسط زمن تشفيل القطعه \\
\hline
\end{tabular}

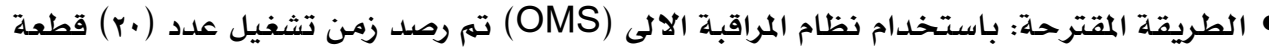

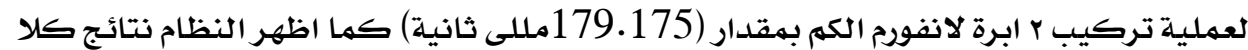

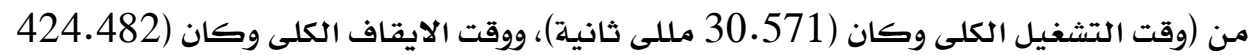

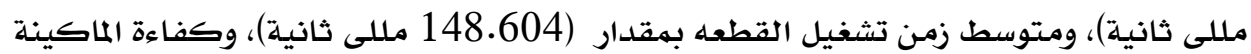

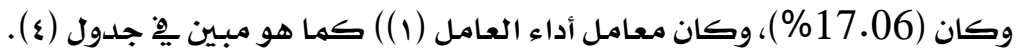


جدول (ع) نتائج مراقبة عملية تركيب r ابرة لانفورم الكم بالطريقة المقترحة (OMS).

\begin{tabular}{|c|c|c|c|}
\hline الزمن الكلى (بالمللى ثانية) & وقت ايقاف (بالمللى ثانية) & وقت تشفيل (بالمللى ثانية) & عدد القطع \\
\hline 7543 & 6386 & 1157 & 1 \\
\hline 15785 & 14383 & 1402 & 2 \\
\hline 9450 & 8070 & 1380 & 3 \\
\hline 5568 & 4089 & 1479 & 4 \\
\hline 11758 & 10615 & 1143 & 5 \\
\hline 7249 & 5833 & 1416 & 6 \\
\hline 12686 & 11141 & 1545 & 7 \\
\hline 6208 & 5137 & 1071 & 8 \\
\hline 10501 & 9296 & 1205 & 9 \\
\hline 10742 & 9110 & 1632 & 10 \\
\hline 5265 & 3559 & 1706 & 11 \\
\hline 7220 & 5264 & 1956 & 12 \\
\hline 5783 & 4079 & 1704 & 13 \\
\hline 6235 & 4608 & 1627 & 15 \\
\hline 5925 & 4148 & 1777 & 16 \\
\hline 6230 & 4268 & 1962 & 17 \\
\hline 5454 & 3852 & 1602 & 18 \\
\hline 18707 & 17105 & 1602 & 19 \\
\hline 5378 & 3735 & 1643 & 20 \\
\hline 30571 & \multicolumn{3}{|c|}{ وقت التشفيل الكلى (بالمللى ثانية) } \\
\hline 148604 & \multicolumn{3}{|c|}{ وقت الايقاف الكلى (بالمللى ثانية) } \\
\hline 179175 & \multicolumn{3}{|c|}{ اجمالى الوقت المستفرق للقطع (بالمللى ثانية) } \\
\hline 8958.75099 & \multicolumn{3}{|c|}{ متوسط زمن تشفيل القطعه (بالمللى ثانية) } \\
\hline 17.06 & \multicolumn{3}{|c|}{ ) ( } \\
\hline 1 & \multicolumn{3}{|c|}{ معامل اداء العامل } \\
\hline
\end{tabular}

وبالمثل تم قياس باقي العمليات 


\section{r- r مقارنة قياسات متوسط زمن عملليات التشغيل للطريقتين:}

يتضح من شكل ( • ) ان عملية (تركيب تيكيت وعراقة) حققت اعلى متوسط زمسن تشغيلى

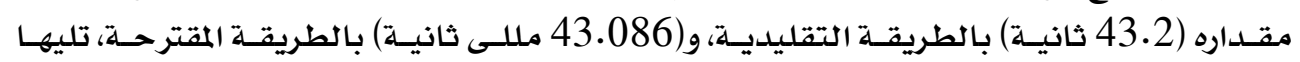

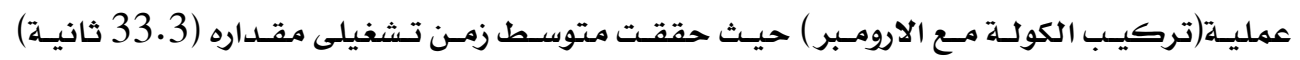

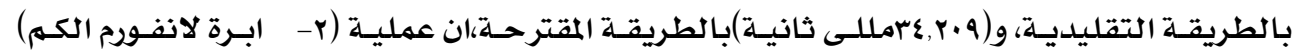

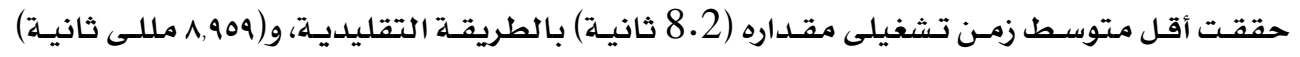

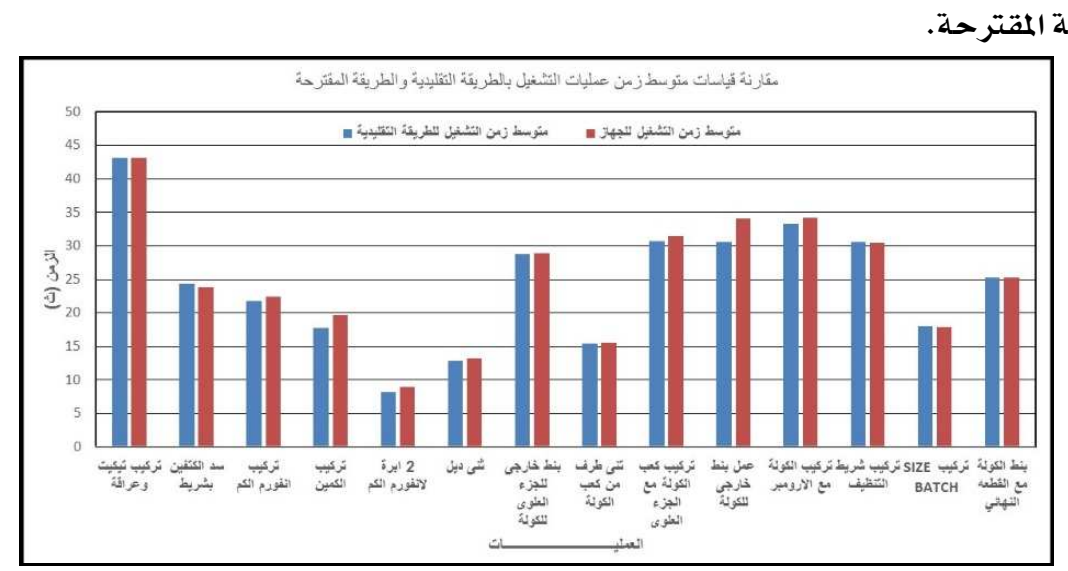

شكل ( (1) مقارنة قياسات متوسط زمن عملليات التشغيل للطريقتين

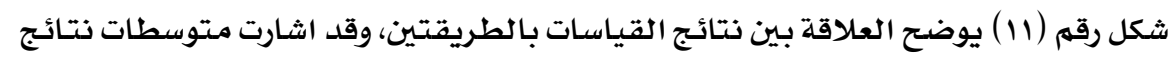

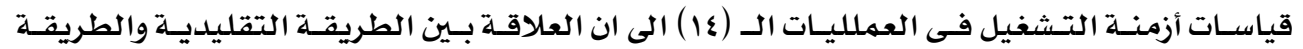
المقترحة تتبع المعادلة

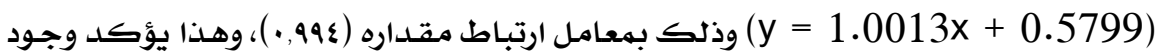

علاقة ارتباط طردية قوية بين الطريقتين.

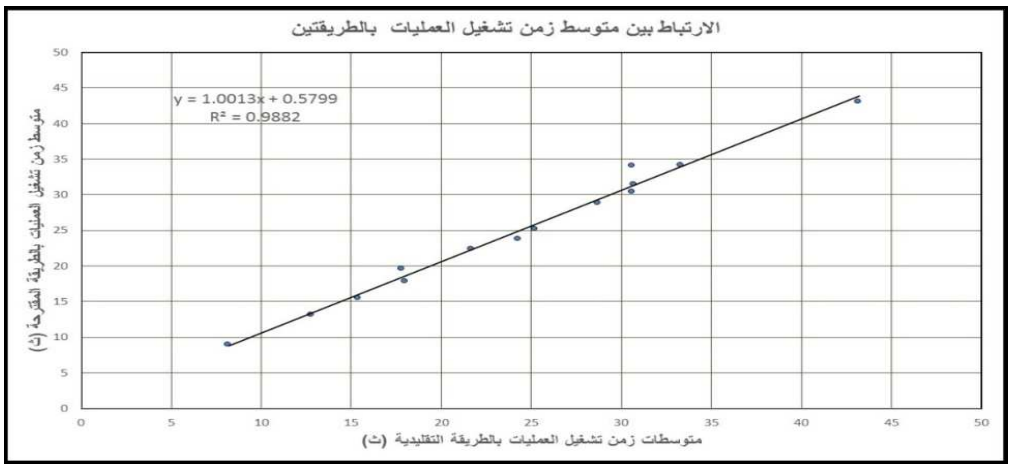

شكل (11) الارتباط بين متوسط زمن عمليات التشغيل بالطريقتين 
مـن النتائج التـى تم التوصل اليها والتى أظهـرت ان هنـاك علاقـة ارتبـاط طرديـة قويـة بـين

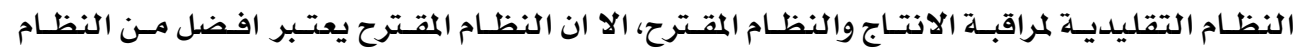

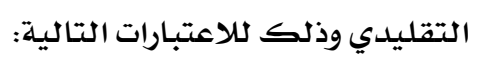

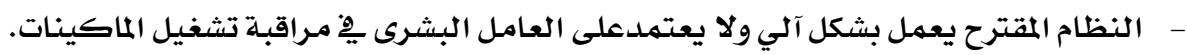

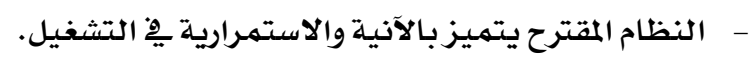

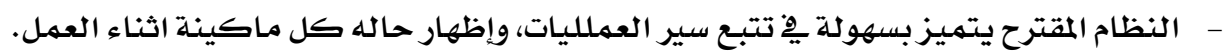

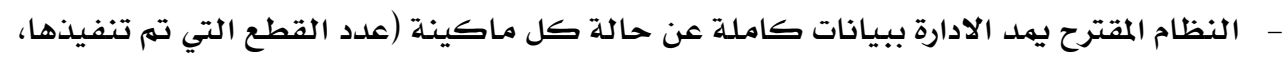

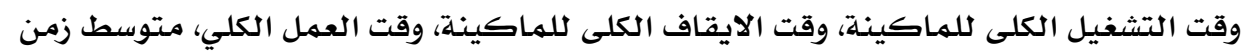

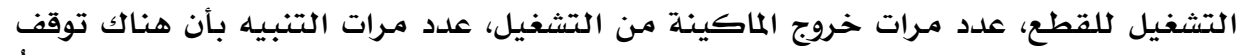

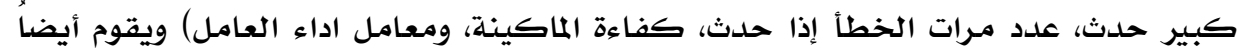

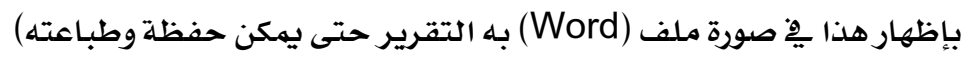

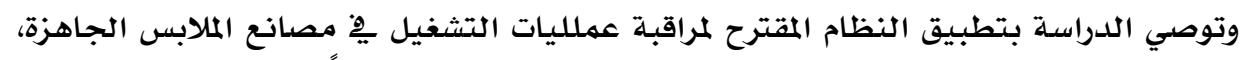

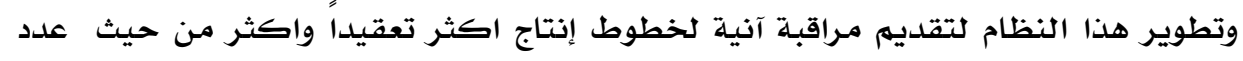
الماكينات وتنوع العملليات بشكل مستمر ومتوازن.

0. المراجع:

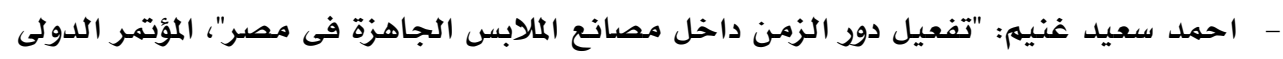

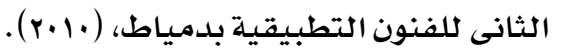

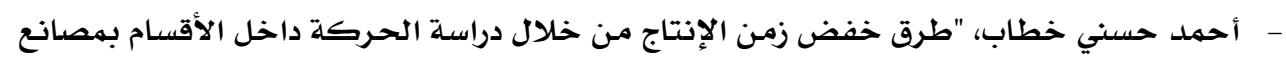

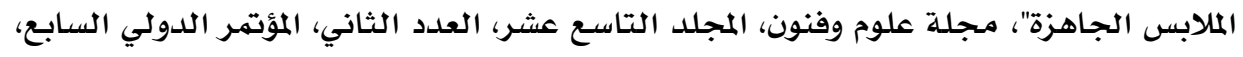

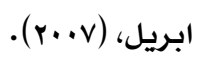

بهاء الدين اسماعيل رأفت، سوسن عبد اللطيف رزق، عادل ابراهيم جمعـة: "نظام معلوماتي

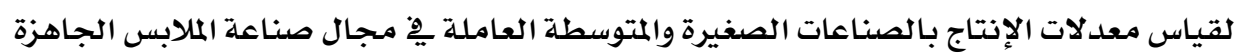

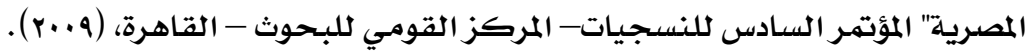

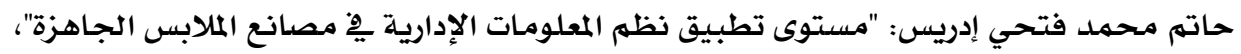

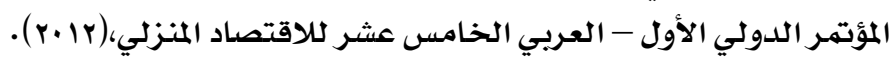

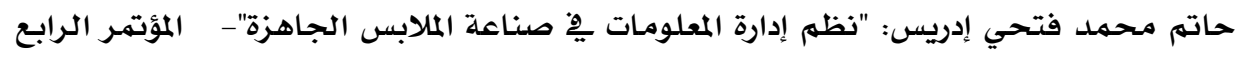

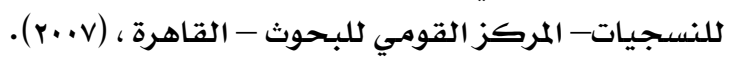

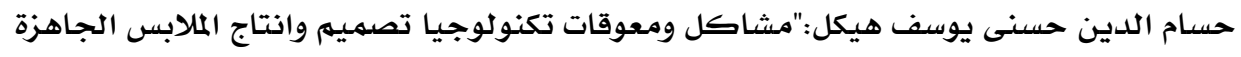

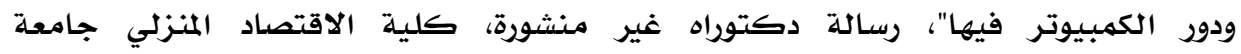

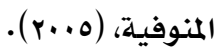




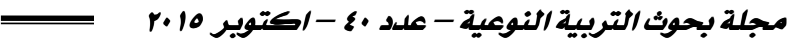

- حسام هيكل، أحمد غنيه: "تقييم دراسة الحركة بنظام البيانات العامة للحياكة (GSD)

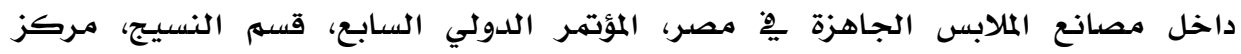

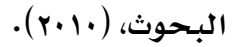

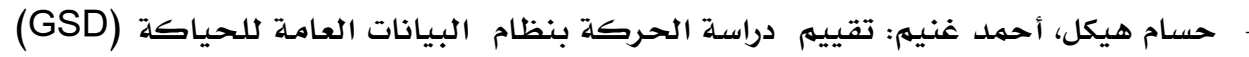

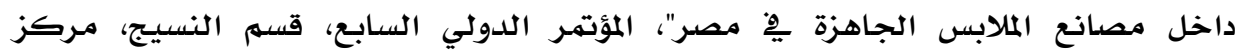

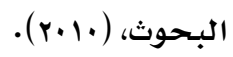
رامي سعيد مصطفى: "إمكانية بناء نظام الكتروني لدعم الادارة الفنية تجاه الأنتاج المتغير

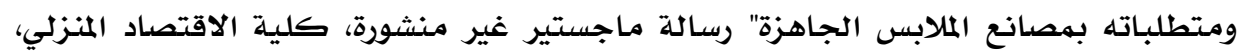

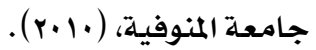

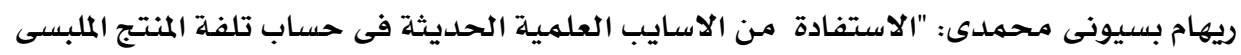

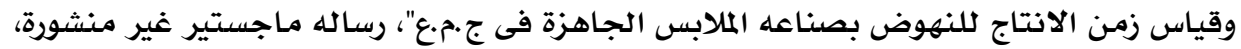

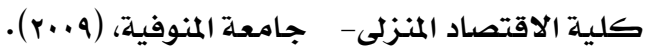

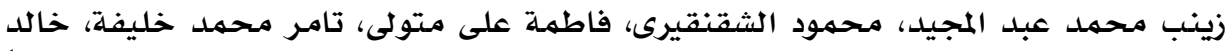

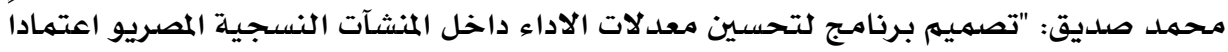

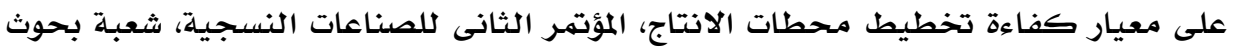

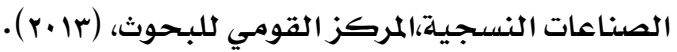

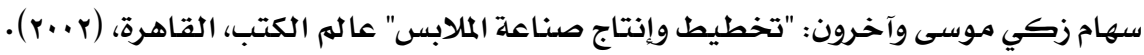

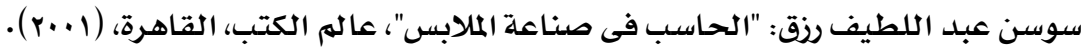

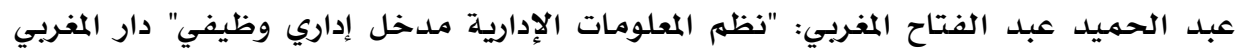

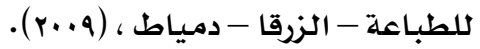

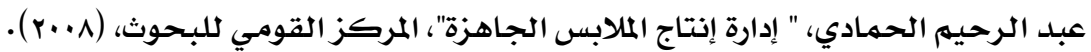

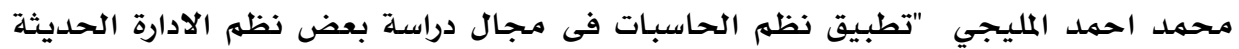

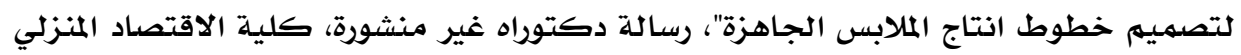

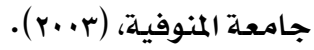

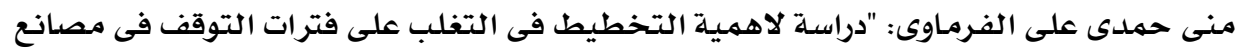

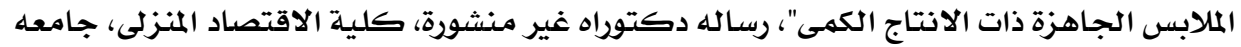

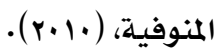
يسرية فراج: "ادارة عملليات النقل بين الحاضـروآفاق المستقبل"- الإسـراء- القاهرة، (r..r). 
- C. A. Anam RASHED, Nasima BAGUM, Sifullah KHAN, Mehedi HASAN .A MODEL ON FACTORY INFORMATION SYSTEM (FIS), Review of General Management, 2011.

- Gorge Hodge, William Oxenham, YatinKarpe, HasanCete, Stacey Schertel, SedelUncu, \& Neil Cahil: "Information Engineering: Textile Industry's ValueAdding Key to Effective Decision Making" National Textile Center Annual Report, Nov. 2000.

- http://www.zymmetry.com/news/tc/18-1/rfid 


\title{
Computer-based System for Production Monitoring in Ready Made Garments' Factories
}

\author{
Mostafa A. Badawy Hatem M. F. Idrees Shady Ebraheem H. \\ RMG. Dept. \\ RMG. Dept. \\ Tex. Engineering Dept. \\ Fac. of App. Arts, \\ Fac. of App. Arts, \\ Damietta University \\ Damietta University \\ Fac. of Engineering, \\ Mansoura University
}

\begin{abstract}
:
Garment industry is one of the industries that needs to be successively developed to cope with the ongoing global developments. There are many attempts to use the computer and applied technology in all aspects of garment production, however most factories in Egypt depend on manual recording to follow up the production and to evaluate the efficiency of workers.In this study, a computer-based system is introduced to monitor the production in the garment factories. The system automatically records the working time for each machine in real time to calculate machine and worker performance. It will also identify the production bottlenecks in a timely manner and establish regular reports that would help the administration evaluating the situation at any time. The results of proposed system showed a very good agreement when compared to the results of regular monitoring that depends on human observer with stop watch who calculates the worker performance based on the average production time. The study recommended applying the proposed this system in the garment factories and developing the system to be able to work in more complicated production lines which have larger number of machines with different processes.
\end{abstract}

